\title{
CUSTO DE PRODUÇÃO DE MUDAS DE ABACAXIZEIRO MICROPROPAGADAS
}

Juliana Aparecida de Souza ${ }^{1}$, Jaine Aparecida de Camargo ${ }^{2}$, Maria Aparecida Anselmo Tarsitano $^{3}$, Luiz de Souza Corrêa ${ }^{3}$

\footnotetext{
${ }^{1}$ Eng. Agrônoma, Mestre pela UNESP Campus de Ilha Solteira (SP), julianasouzaagro@ yahoo.com.br.

${ }^{2}$ Doutoranda em Agronomia pela UNESP Campus de Ilha Solteira (SP), inecamargo_agr@yahoo.com.br

${ }^{3}$ Professores do Departamento de Fitotecnia, Tecnologia de Alimentos e Sócio Economia da UNESP Campus de Ilha Solteira (SP), maat@agr.feis.unesp.br, lcorrea@agr.feis.unesp.br
}

RESUMO: A partir da propagação in vitro podem-se produzir rapidamente grandes quantidades de mudas de abacaxizeiro geneticamente uniformes e de excelente sanidade. Porém, apesar destas vantagens, o seu custo é elevado. O trabalho teve como objetivo estudar o custo de produção de mudas de abacaxizeiro micropropagadas. O custo de produção das mudas de abacaxizeiro foi obtido baseado na análise dos procedimentos de micropropagação descritos na literatura. Os preços dos insumos foram levantados junto ao Laboratório de Micropropagação da UNESP de Ilha Solteira. O meio básico utilizado é o de Murashige \& Skoog (MS). Considerou-se a inoculação das gemas em tubos de ensaio e a multiplicação em frascos. Adotou-se como referência 100 gemas inoculadas inicialmente a partir de 10 mudas, com uma taxa de desenvolvimento de $60 \%$ e uma taxa de multiplicação de 1000 plântulas por gema. Ao final do processo deve ser obtido algo em torno de 60.000 mudas micropropagadas, considerando-se que não ocorram perdas na fase de aclimatação. $\mathrm{O}$ custo de produção foi estimado em R $\$ 0,46$ por muda, o que corresponde de $89 \%$ a $94 \%$ a mais que o custo de uma muda convencional. Desta forma, conclui-se que o alto custo de produção das mudas de abacaxizeiro micropropagadas é o principal fator que tem limitado a sua utilização em lavouras comerciais.

Palavras-chave: Cultivo in vitro. Biotecnologia. Produção de mudas.

\section{PRODUCTION COST OF MICROPROPAGATED PINEAPPLE PLANTS}

\begin{abstract}
From the in vitro propagation can quickly produce large quantities of pineapple plantlets, genetically uniform and excellent health. However, despite these advantages, its cost is high. The work aimed to study the cost of pineapple plantlets micropropagated production. The cost of production of the pineapple seedlings was obtained based on analysis of micropropagation procedures described in the literature. The price of inputs was collected from Micropropagation Laboratory of UNESP in Ilha Solteira - SP - Brazil. The basic medium used is the Murashige and Skoog (MS). Shoots were inoculated in test tubes and flasks multiplied. We adopted as reference 100 initially inoculated buds from 10 trees, only $60 \%$ are developing and the multiplication rate is 1000 per bud seedlings will be obtained when the process ends somewhere around 60 thousand plantlets, whereas no losses occurring during the acclimatization. The production cost was
\end{abstract}


estimated at $\mathrm{R} \$ 0.46 /$ plant, which represents $89 \%$ to $94 \%$ more than the cost of a conventional switches. Thus, we conclude that this is the main factor that has limited their use in commercial fields.

Key words: In vitro culture. Biotechnology. Manufacturing of plants.

\section{INTRODUÇÃO}

O método convencional de propagação do abacaxizeiro é feito por meio de mudas formadas a partir de brotações laterais da planta, denominadas filhote, filhote-rebentão ou rebentão. A coroa dos frutos também pode constituir material propagativo, embora não seja muito utilizada, já que acompanha o fruto na época da comercialização. É possível também obter mudas através de métodos de seccionamento do caule, destruição do meristema apical, tratamento químico durante a diferenciação floral e por cultura de tecidos (REINHARDT; CUNHA, 1999).

A utilização de mudas sadias assegura a qualidade do material propagativo utilizado e, consequentemente, o bom desenvolvimento do plantio e baixa incidência de problemas fitossanitários. Desta forma, visando aumentar e acelerar a taxa de multiplicação e, ao mesmo tempo, diminuir o potencial ou até mesmo evitar a disseminação de pragas e doenças via muda convencional, técnicas de cultura de tecidos têm sido empregadas para a propagação in vitro do abacaxizeiro. No laboratório, num espaço físico reduzido e sob condições de temperatura e luminosidade controladas, pode-se produzir rapidamente grandes quantidades de mudas de abacaxizeiro, geneticamente uniformes e de excelente sanidade, sejam de cultivares recomendada ou de novos genótipos gerados pela pesquisa (MATOS et al., 2009).

Teixeira et al. (2011) enumera várias vantagens e desvantagens na produção de mudas de abacaxizeiro micropropagadas. Entre as vantagens, podemos citar: alto vigor e uniformidade; ausência de pragas e doenças; mudas enraizadas e prontas para ser cultivadas no campo; disponibilidade de acordo com a demanda em termos de época e local de plantio. Entre as desvantagens: o custo da muda é alto; a produção depende de infraestrutura relativamente sofisticada; investimento inicial para montagem do laboratório, casas de vegetação e telado é alto; o processo requer mão-de-obra especializada, consequentemente melhor remunerada; e a metodologia está em constante evolução, o que requer atualização freqüente do processo de produção.

Neste sentido, a micropropagação de mudas de abacaxizeiro é tema de várias pesquisas. Guerra et al. (1999), estudaram o estabelecimento de um protocolo regenerativo, Macedo et al. (2003) avaliaram diferentes concentrações de ANA e BAP no cultivo hidropônico das plântulas obtidas in vitro e Silva et al. (1998), estudaram a ação de agromix ${ }^{\circledR}$, húmus e kelpak na aclimatação das mudas. Neste sentido, o trabalho teve como objetivo determinar o custo de produção de mudas de abacaxizeiro micropropagadas.

Cultura Agronômica, Ilha Solteira, v.24, n.1, p.45-52, 2015 


\section{MATERIAL E MÉTODOS}

A produção de mudas de abacaxizeiro via cultura de tecidos consiste na regeneração de plantas completas (caule, folhas e raízes) a partir de gemas axilares de plantas matrizes selecionadas no campo, em plantios comerciais. O processo envolve várias etapas, começando com a coleta das mudas de plantas selecionadas no campo, passa pela extração das gemas axilares, cultivo e regeneração das plântulas, as quais são, numa segunda etapa, inoculadas em meio de multiplicação. Após essa fase, os brotos são cultivados em meio próprio para alongamento/enraizamento. Finalmente, as plântulas são transferidas para casa de vegetação para aclimatação, crescimento e desenvolvimento.

O custo de produção das mudas de abacaxizeiro foi obtido baseado na análise dos procedimentos de micropropagação descrito por Teixeira et al. (2011), discriminados a seguir. Foi adotada a colheita de dez mudas do tipo filhote, filhote-rebentão, rebentão ou coroa, retiradas da planta mãe. A partir de cada muda é possível extrair de dez a quinze gemas axilares, dessa forma, considerou-se a extração de 10 gemas por muda, totalizando 100 gemas. Na desinfestação das gemas foi considerado o uso de álcool etílico comercial e hipoclorito de sódio, na concentração de $70 \%$ e $1 \%$, respectivamente.

O meio básico adotado é o de Murashige \& Skoog (1962), suplementados com 2 mg $\mathrm{L}^{-1}$ de glicina, $100 \mathrm{mg} \mathrm{L}^{-1}$ de myo-inositol, $30 \mathrm{~g} \mathrm{~L}^{-1}$ de sacarose, 7,0 $\mathrm{g} \mathrm{L}^{-1}$ de Agar e 2,5 $\mathrm{g} \mathrm{L}^{-1}$ de fitagel, além dos fitorreguladores BAP (6-benzilaminopurina) e ANA (ácido naftalenoacético) respectivamente, nas concentrações de 0,5 e $0,125 \mathrm{mg} \mathrm{L}^{-1}$, na fase de estabelecimento e 2 e $0,5 \mathrm{mg} \mathrm{L}^{-1}$, na fase de multiplicação. Foi considerada uma inoculação de 100 gemas em tubos de ensaio $(25 \mathrm{x} 15 \mathrm{~mm})$, com $15 \mathrm{~mL}$ de meio de cultura e os brotos subcultivados em frascos com $30 \mathrm{~mL}$ de meio de cultura com seis gemas por frasco, sendo realizados três subcultivos com intervalo de 30 dias (30, 60 e 90 dias após a inoculação). Após esse período, ocorre a transferência dos brotos para meio sem reguladores de crescimento, denominado meio de alongamento/enraizamento. Nesse meio, as gemas, que estavam em processo ativo de multiplicação originam, após 45 a 60 dias, pequenas mudas de abacaxizeiro. As mudas são tratadas com Benlate $(0,1 \%)$, transplantadas para sacolas plásticas (1L) contendo substrato comercial (Bioplant®) e transferidas para telados ou casa de vegetação, onde permanecem por um período de 6 a 8 meses para aclimatação.

Considerando-se que, de 100 gemas inoculadas inicialmente a partir de 10 mudas, apenas $60 \%$ se desenvolvem e que a taxa de multiplicação seja de 1000 plântulas por gema, será obtido ao final do processo algo em torno de 60.000 mudas micropropagadas, considerando-se que não ocorram perdas na fase de aclimatação. Considerando-se ainda as 100.000 mudas iniciais, a quantidade de meio de cultura utilizado nas fases de estabelecimento, multiplicação e enraizamento, correspondem respectivamente a 1,5L;100L e 300L.

Os preços dos insumos foram levantados junto aos responsáveis pelo laboratório de Micropropagação da UNESP de Ilha Solteira. Para a análise econômica, elaborou-se o custo operacional de produção, conforme Martin et al. (1998). Estimou-se o Custo Operacional

Cultura Agronômica, Ilha Solteira, v.24, n.1, p.45-52, 2015 
Efetivo (COE) como sendo as despesas com os materiais consumidos e mão de obra. Considerando-se as dificuldades para se levantar as despesas com mão de obra, utilizou-se a estimativa obtida em Teixeira et al. (2011), em que este valor representa aproximadamente $60 \%$ do custo de produção da muda. Foram acrescentadas outras despesas operacionais (água, energia elétrica, dentre outras). Não foram estimados os valores das depreciações com o investimento necessário (laboratório, casa de vegetação, entre outros). Na tabela apresentada, as operações realizadas na micropropagação foram dividas em etapas ou itens e subitens. O processo foi dividido em três etapas, descritas como desinfestação das gemas; cultivo in vitro: estabelecimento, multiplicação e enraizamento e aclimatação.

\section{RESULTADOS E DISCUSSÃO}

Na Tabela 1 encontra-se a estimativa do custo operacional efetivo (COE) obtido na micropropagação de mudas de abacaxizeiro. De acordo com a estimativa, o COE é de aproximadamente $\mathrm{R} \$ 0,46$ por muda. Dos $38,1 \%$ gastos com materiais de consumo, os maiores custos obtidos 23,2 e $14,9 \%$, representam a aclimatação e o cultivo in vitro. Sendo que, na fase de aclimatação, 21,9\% dos custos é representado pelo substrato comercial e no cultivo in vitro, 10,2, 4,6 e 1\% corresponde respectivamente às fases de enraizamento, multiplicação e estabelecimento, Resultado este justificado através das diferentes quantidades de meio de cultura utilizado nas diferentes fases.

Tabela 1. Estimativa do custo operacional efetivo (COE) obtidos na produção de 60.000 de mudas de abacaxizeiro micropropagadas. Ilha Solteira, Maio de 2011.

\begin{tabular}{|c|c|c|c|c|c|}
\hline Especificação & Unidade & $\begin{array}{l}\text { Concentração } \\
\qquad\left(\mathrm{g} \mathrm{L}^{-1}\right)\end{array}$ & $\begin{array}{c}\text { Qtde } \\
\text { (L) }\end{array}$ & $\begin{array}{l}\text { Valor/ unidade } \\
\quad(\mathbf{R} \$)\end{array}$ & $\begin{array}{l}\text { Valor Total } \\
\quad(\mathbf{R} \$)\end{array}$ \\
\hline \multicolumn{6}{|c|}{ 1. Desinfestação das gemas } \\
\hline Álcool etílico & $\mathrm{L}$ & 0,754 & 0,1 & 3,80 & 0,29 \\
\hline Hipoclorito de sódio & $\mathrm{L}$ & 0,400 & 0,1 & 1,50 & 0,06 \\
\hline Subtotal 1 & & & & & 0,35 \\
\hline \multicolumn{6}{|l|}{$\begin{array}{l}\text { 2. Cultivo in vitro } \\
\text { 2.1 Estabelecimento }\end{array}$} \\
\hline $\mathrm{NH}_{4} \mathrm{NO}_{3}$ & $\mathrm{~g}$ & 1,650 & 1,5 & 0,01 & 0,03 \\
\hline $\mathrm{KNO}_{3}$ & $\mathrm{~g}$ & 1,900 & 1,5 & 0,54 & 1,54 \\
\hline $\mathrm{H}_{3} \mathrm{BO}_{3}$ & $\mathrm{~g}$ & 0,012 & 1,5 & 0,01 & $1,8 \times 10^{-4}$ \\
\hline $\mathrm{KH}_{2} \mathrm{PO}_{4}$ & $\mathrm{~g}$ & 0,340 & 1,5 & 0,02 & 0,01 \\
\hline $\mathrm{KI}$ & $\mathrm{g}$ & 0,002 & 1,5 & 0,04 & 0,00 \\
\hline $\mathrm{Na}_{2} \mathrm{MoO}_{4} \cdot 2 \mathrm{H}_{2} \mathrm{O}$ & $\mathrm{g}$ & 0,0005 & 1,5 & 0,10 & 0,00 \\
\hline $\mathrm{CoCl}_{2} \cdot 2 \mathrm{H}_{2} \mathrm{O}$ & $\mathrm{g}$ & 0,0001 & 1,5 & 0,07 & $1,05 \times 10^{-5}$ \\
\hline $\mathrm{CaCl}_{2} \cdot 2 \mathrm{H}_{2} \mathrm{O}$ & $\mathrm{g}$ & 0,09 & 1,5 & 0,01 & 0,00 \\
\hline $\mathrm{MgSO}_{4} .7 \mathrm{H}_{2} \mathrm{O}$ & $\mathrm{g}$ & 0,74 & 1,5 & 0,01 & 0,01 \\
\hline $\mathrm{MnSO}_{4} .4 \mathrm{H}_{2} \mathrm{O}$ & $\mathrm{g}$ & 0,04 & 1,5 & 0,02 & 0,00 \\
\hline $\mathrm{ZnSO}_{4} .7 \mathrm{H}_{2} \mathrm{O}$ & $\mathrm{g}$ & 0,02 & 1,5 & 0,03 & 0,00 \\
\hline $\mathrm{CuSO}_{4} .5 \mathrm{H}_{2} \mathrm{O}$ & $\mathrm{g}$ & 0,0001 & 1,5 & 0,40 & 0,00 \\
\hline $\mathrm{Na}_{2}$ EDTA. $2 \mathrm{H}_{2} \mathrm{O}$ & $\mathrm{g}$ & 0,07 & 1,5 & 0,07 & 0,01 \\
\hline $\mathrm{FeSO}_{4} .7 \mathrm{H}_{2} \mathrm{O}$ & $\mathrm{g}$ & 0,06 & 1,5 & 0,01 & 0,00 \\
\hline
\end{tabular}

Cultura Agronômica, Ilha Solteira, v.24, n.1, p.45-52, 2015 
continuação

\begin{tabular}{|c|c|c|c|c|c|}
\hline Especificação & Unidade & $\begin{array}{c}\text { Concentração } \\
\left(\mathrm{g} \mathrm{L}^{-1}\right)\end{array}$ & $\begin{array}{l}\text { Qtde } \\
\text { (L) }\end{array}$ & $\begin{array}{l}\text { Valor/unidade } \\
\text { (R\$) }\end{array}$ & $\begin{array}{l}\text { Valor Total } \\
\quad \text { (R\$) }\end{array}$ \\
\hline Hexitol & $\mathrm{g}$ & 0,10 & 1,5 & 2,63 & 0,39 \\
\hline Tiamina & $\mathrm{g}$ & 0,001 & 1,5 & 0,48 & 0,00 \\
\hline Ácido Nicotínico & $\mathrm{g}$ & 0,001 & 1,5 & 27,65 & 0,02 \\
\hline Piridoxina & $\mathrm{g}$ & 0,001 & 1,5 & 218,00 & 0,16 \\
\hline Glicina & $\mathrm{g}$ & 0,0020 & 1,5 & 0,05 & 0,00 \\
\hline Sacarose & $\mathrm{g}$ & 30,00 & 1,5 & 0,14 & 6,30 \\
\hline Agar & $\mathrm{g}$ & 7,00 & 1,5 & 0,66 & 6,90 \\
\hline Fitagel & & 2,50 & 1,5 & 0,97 & 3,63 \\
\hline Ácido naftalenoacético & $\mathrm{g}$ & 0,000125 & 1,5 & 2,50 & 0,00 \\
\hline Benzilaminopurina & $\mathrm{g}$ & 0,0005 & 1,5 & 15,00 & 0,011 \\
\hline $\begin{array}{r}\text { Subtotal } 2.1 \\
\end{array}$ & & & & & 19,03 \\
\hline \multicolumn{6}{|l|}{ 2.2 Multiplicação } \\
\hline $\mathrm{NH}_{4} \mathrm{NO}_{3}$ & $\mathrm{~g}$ & 1,65 & 100 & 0,01 & 2,01 \\
\hline $\mathrm{KNO}_{3}$ & $\mathrm{~g}$ & 1,90 & 100 & 0,54 & 102,60 \\
\hline $\mathrm{H} 3 \mathrm{BO} 3$ & $\mathrm{~g}$ & 0,01 & 100 & 0,01 & 0,02 \\
\hline $\mathrm{KH}_{2} \mathrm{PO}_{4}$ & $\mathrm{~g}$ & 0,34 & 100 & 0,02 & 0,71 \\
\hline $\mathrm{KI}$ & $\mathrm{g}$ & 0,00 & 100 & 0,04 & 0,01 \\
\hline $\mathrm{Na}_{2} \mathrm{MoO} 4.2 \mathrm{H}_{2} \mathrm{O}$ & $\mathrm{g}$ & 0,00 & 100 & 0,10 & 0,01 \\
\hline $\mathrm{CoCl}_{2} .2 \mathrm{H}_{2} \mathrm{O}$ & g & 0,00 & 100 & 0,07 & 0,00 \\
\hline $\mathrm{CaCl}_{2} \cdot 2 \mathrm{H}_{2} \mathrm{O}$ & $\mathrm{g}$ & 0,09 & 100 & 0,01 & 0,12 \\
\hline $\mathrm{MgSO}_{4} \cdot 7 \mathrm{H}_{2} \mathrm{O}$ & $\mathrm{g}$ & 0,74 & 100 & 0,01 & 0,59 \\
\hline $\mathrm{MnSO}_{4} .4 \mathrm{H}_{2} \mathrm{O}$ & $\mathrm{g}$ & 0,04 & 100 & 0,02 & 0,09 \\
\hline $\mathrm{ZnSO}_{4} .7 \mathrm{H}_{2} \mathrm{O}$ & $\mathrm{g}$ & 0,02 & 100 & 0,03 & 0,04 \\
\hline $\mathrm{CuSO}_{4} .5 \mathrm{H}_{2} \mathrm{O}$ & $\mathrm{g}$ & 0,00 & 100 & 0,40 & 0,00 \\
\hline $\mathrm{Na}_{2}$ EDTA. $2 \mathrm{H}_{2} \mathrm{O}$ & $\mathrm{g}$ & 0,07 & 100 & 0,07 & 0,50 \\
\hline $\mathrm{FeSO}_{4} \cdot 7 \mathrm{H}_{2} \mathrm{O}$ & $\mathrm{g}$ & 0,06 & 100 & 0,01 & 0,07 \\
\hline Hexitol & $\mathrm{g}$ & 0,10 & 100 & 2,63 & 26,30 \\
\hline Tiamina & $\mathrm{g}$ & 0,00 & 100 & 0,48 & 0,02 \\
\hline Ácido Nicotínico & $\mathrm{g}$ & 0,00 & 100 & 27,65 & 1,38 \\
\hline Piridoxina & $\mathrm{g}$ & 0,00 & 100 & 218,00 & 10,90 \\
\hline Glicina & $\mathrm{g}$ & 0,00 & 100 & 0,05 & 0,01 \\
\hline Sacarose & $\mathrm{g}$ & 30,00 & 100 & 0,14 & 420,00 \\
\hline Agar & $\mathrm{g}$ & 7,00 & 100 & 0,66 & 459,90 \\
\hline Fitagel & & 2,50 & 100 & 0,97 & 242,25 \\
\hline Ácido naftalenoacético & g & 0,0005 & 100 & 2,50 & 0,13 \\
\hline Benzilaminopurina & $\mathrm{g}$ & 0,0020 & 100 & 15,00 & 3,00 \\
\hline Subtotal 2.2 & & & & & $1.270,66$ \\
\hline \multicolumn{6}{|l|}{ 2.3 Enraizamento } \\
\hline $\mathrm{NH}_{4} \mathrm{NO}_{3}$ & $\mathrm{~g}$ & 1,65 & 300 & 0,01 & 6,04 \\
\hline $\mathrm{KNO}_{3}$ & $\mathrm{~g}$ & 1,90 & 300 & 0,54 & 307,80 \\
\hline $\mathrm{H}_{3} \mathrm{BO}_{3}$ & $\mathrm{~g}$ & 0,01 & 300 & 0,01 & 0,05 \\
\hline $\mathrm{KH}_{2} \mathrm{PO}_{4}$ & $\mathrm{~g}$ & 0,34 & 300 & 0,02 & 2,14 \\
\hline KI & $\mathrm{g}$ & 0,00 & 300 & 0,04 & 0,02 \\
\hline $\mathrm{Na}_{2} \mathrm{MoO}_{4} \cdot 2 \mathrm{H}_{2} \mathrm{O}$ & g & 0,00 & 300 & 0,10 & 0,02 \\
\hline $\mathrm{CoCl}_{2} \cdot 2 \mathrm{H}_{2} \mathrm{O}$ & $\mathrm{g}$ & 0,00 & 300 & 0,07 & 0,00 \\
\hline $\mathrm{CaCl} 2.2 \mathrm{H}_{2} \mathrm{O}$ & $\mathrm{g}$ & 0,09 & 300 & 0,01 & 0,35 \\
\hline $\mathrm{MgSO}_{4} .7 \mathrm{H}_{2} \mathrm{O}$ & $\mathrm{g}$ & 0,74 & 300 & 0,01 & 1,78 \\
\hline $\mathrm{MnSO}_{4} .4 \mathrm{H}_{2} \mathrm{O}$ & $\mathrm{g}$ & 0,04 & 300 & 0,02 & 0,27 \\
\hline
\end{tabular}

Cultura Agronômica, Ilha Solteira, v.24, n.1, p.45-52, 2015 


\begin{tabular}{|c|c|c|c|c|c|}
\hline Especificação & Unidade & $\begin{array}{c}\text { Concentração } \\
\left(\mathrm{g} \mathrm{L}^{-1}\right)\end{array}$ & $\begin{array}{l}\text { Qtde } \\
\text { (L) }\end{array}$ & $\begin{array}{c}\text { Valor/unidade } \\
\text { (R\$) }\end{array}$ & $\begin{array}{l}\text { Valor Total } \\
\quad(\mathbf{R} \$)\end{array}$ \\
\hline $\mathrm{ZnSO}_{4} .7 \mathrm{H}_{2} \mathrm{O}$ & $\mathrm{g}$ & 0,02 & 300 & 0,03 & 0,13 \\
\hline $\mathrm{CuSO}_{4} .5 \mathrm{H}_{2} \mathrm{O}$ & $\mathrm{g}$ & 0,00 & 300 & 0,40 & 0,01 \\
\hline $\mathrm{Na}_{2}$ EDTA. $2 \mathrm{H}_{2} \mathrm{O}$ & $\mathrm{g}$ & 0,07 & 300 & 0,07 & 1,50 \\
\hline $\mathrm{FeSO}_{4} \cdot 7 \mathrm{H}_{2} \mathrm{O}$ & $\mathrm{g}$ & 0,06 & 300 & 0,01 & 0,20 \\
\hline Hexitol & $\mathrm{g}$ & 0,10 & 300 & 2,63 & 78,90 \\
\hline Tiamina & $\mathrm{g}$ & 0,00 & 300 & 0,48 & 0,07 \\
\hline Ácido Nicotínico & $\mathrm{g}$ & 0,00 & 300 & 27,65 & 4,15 \\
\hline Piridoxina & $\mathrm{g}$ & 0,00 & 300 & 218,00 & 32,70 \\
\hline Glicina & $\mathrm{g}$ & 0,00 & 300 & 0,05 & 0,03 \\
\hline Sacarose & $\mathrm{g}$ & 30,00 & 300 & 0,14 & $1.260,00$ \\
\hline Agar & $\mathrm{g}$ & 7,00 & 300 & 0,66 & $1.379,70$ \\
\hline Fitagel & $\mathrm{g}$ & 2,50 & 300 & 0,97 & 726,75 \\
\hline Subtotal 2.3 & & & & & $2.795,14$ \\
\hline Subtotal 2 & & & & & $4.084,82$ \\
\hline \multicolumn{6}{|l|}{ 3. Aclimatação } \\
\hline Benlate & $\mathrm{kg}$ & 0,001 & 1 & 150,00 & 150,00 \\
\hline Sacola plástica & unidade & & 60.000 & 0,003 & 180,00 \\
\hline Substrato & $\mathrm{m}^{3}$ & & 60 & 100,00 & $6.000,00$ \\
\hline Subtotal 3 & & & & & $6.330,00$ \\
\hline Subtotal geral & & & & & $10.415,16$ \\
\hline Mão de obra (60\% COE) & & & & & $15.622,75$ \\
\hline Outras despesas $(5 \% \mathrm{CO}$ & & & & & $1.301,90$ \\
\hline \multicolumn{5}{|c|}{ Custo Operacional Efetivo (COE) } & $27.339,81$ \\
\hline COE/muda & & & & & 0,46 \\
\hline
\end{tabular}

$\mathrm{O}$ custo de $\mathrm{R} \$ 0,46$ por muda é maior que o valor citado por Teixeira et al. (2011), que segundo os autores, o custo da muda gira em torno de $\mathrm{R} \$ 0,20$ a $\mathrm{R} \$ 0,30$, bem superior ao da muda convencional, que está entre $\mathrm{R} \$ 0,03$ a $\mathrm{R} \$ 0,05$. Neste sentido, o custo de produção de uma muda micropropagada pode representar de $89 \%$ a $94 \%$ a mais que o custo de uma muda convencional. Isto ocorre principalmente devido à necessidade de mão de obra constante e especializada no processo de produção da muda. Além disso, cabe ressaltar que a produção das mudas micropropagadas depende ainda da infraestrutura e do investimento inicial alto para montagem do laboratório e casa de vegetação ou telado, fatores estes que não foram considerados na estimativa do cálculo de custo das mudas e consequentemente podem onerar ainda mais o custo de produção das mudas micropropagadas.

No entanto, embora as mudas de abacaxizeiro micropropagadas tenham preços elevados, principal fator que tem limitado a sua utilização em lavouras comerciais, esse tipo de muda pode ser recomendado para fins de pesquisa e outros objetivos. E para viabilizar este tipo de muda em lavouras comerciais, precisam ser desenvolvidos protocolos mais eficientes. 


\section{CONCLUSÕES}

As mudas de abacaxi micropropagadas têm preços elevados, principal fator que tem limitado a sua utilização em lavouras comerciais.

\section{AGRADECIMENTOS}

Aos alunos do Laboratório de Micropropagação da UNESP de Ilha Solteira, Luis Lessi dos Reis e Gustavo Alves Pereira, pela ajuda prestada na execução do trabalho.

\section{REFERÊNCIAS BIBLIOGRÁFICAS}

GUERRA, M. P; VESCO, L. L. D.; PESCADOR, R.; SCHUELTER, A. R.; NODARI, R. O. Estabelecimento de um protocolo regenerativo para a micropropagação do abacaxizeiro. Pesquisa Agropecuária Brasileira, Brasília, v. 34, n. 9, p.1557-1563, 1999.

MACEDO, C. E. C.; SILVA, M. G; NÓBREGA, F. S.; MARTINS, C. P.; BARROSO P. A. V.; ALlOUFA, M. A. I. Concentrações de ANA e BAP na micropropagação de abacaxizeiro 1. Merrill (Ananas comosus) e no cultivo hidropônico das plântulas obtidas in vitro. Revista Brasileira Fruticultura, Jaboticabal, v. 25, n. 3, p.501-504, 2003.

MARTIN, N. B.; SERRA, R.; OLIVEIRA, M. D. M.; ÂNGELO, J. A.; OKAWA, H. Sistema integrado de custos agropecuários - custagri. Informações Econômicas, São Paulo, v. 28, n. 1, p.7-28, 1998.

MATOS, A. P.; REINHARDT, D. H.; SANCHES, N. F.; SOUZA, L. F. S.; Teixeira, F. A.; JUNIOR, J. E.; GOMES, D. C. Produção de mudas sadias de abacaxi. Cruz das Almas: Universidade Federal do Recôncavo da Bahia, 2009. 12 p. (Circular Técnica 89)

MURASHIGE, T.; SKOOG, F. A revised medium for rapid growth and bioassays with tobacco tissue cultures. Physiologia Plantarum, Copenhagen, v. 15, n. 6, p.473-479, 1962.

REINHARDT, H. R. C.; CUNHA, G. A. P. Métodos de propagação. In: CABRAL, J. R. S.; SOUZA, L. F. S. O abacaxizeiro: cultivo, agroindústria e economia. Brasília; Embrapa/Mandioca e Fruticultura, 1999. cap. 5 , p.105-138.

SILVA, A. B.; PASQUAL, M.; MOREIRA, M. A.; MACIEL, A. L. R; ALVES, J. M. C. PEREIRA, A. B. Aclimatação de brotações de abacaxi (Ananas comosus 1.). produzidas in vitro: ação de agromix ${ }^{\circledR}$, húmus e kelpak®. Revista da Universidade Alfenas, Alfenas, n. 4, p.107-110, 1998.

TEIXEIRA, J. B.; CRUZ, A. R. R.; FERREIRA, F. R.; CABRAL, J. R. S. Biotecnologia aplicada à produção de mudas: Produção de mudas micropropagadas de abacaxi. 2011. Cultura Agronômica, Ilha Solteira, v.24, n.1, p.45-52, 2015 
Disponível

em:

<http://www.cenargen.embrapa.br/cenargenda/divulgacao2007/biotecnologianr19.pdf>. Acesso em: 20 Abr. 2012. 